\title{
Evaluation of Combating Desertification Alternatives Using Promethee Model
}

\author{
Mohammad Hassan Sadeghravesh ${ }^{1}$, Hassan Khosravi ${ }^{2}$, Azam Abolhasani ${ }^{3} \&$ Sahar Shekoohizadeghan ${ }^{2}$ \\ ${ }^{1}$ Department of Environment, College of Agriculture, Takestan Branch, Islamic Azad University, Takestan, Iran \\ ${ }^{2}$ Faculty of Natural Resources, University of Tehran, Tehran, Iran \\ ${ }^{3}$ Natural Resources Engineering - Living with the Desert-University of Tehran, Tehran, Iran \\ Correspondence: Hassan Khosravi, Department of Arid and Mountainous Reclamation Region, Faculty of \\ Natural Resources, University of Tehran, Tehran, Iran. Tel: 98-263-222-3044. E-mail: hakhosravi@ut.ac.ir
}

Received: October 2, 2015

Accepted: November 18, $2015 \quad$ Online Published: February 9, 2016

doi:10.5539/jgg.v8n2p1

URL: http://dx.doi.org/10.5539/jgg.v8n2p1

The research is financed by (Sponsoring information)

\begin{abstract}
According to the extent of damage, various effects and complexity of desertification process, selecting appropriate alternatives considering all effective desertification criterions is one of the main concerns of Iran in the field of natural resources. This can be effective in controlling, reclamation of disturbed lands and avoiding destruction areas at desertification risk. This paper tries to provide a systematic and optimal alternatives in a group decision-making model. For this aim, PROMETHEE II method was used for ranking desertification alternatives. At the first in the framework of Multiple Attribute Decision-making (MADM), normalized decision matrix was provided by Delphi model. Then, to ease and accuracy in estimating the criteria preference and alternatives priority, the normalized decision matrix data were entered in Visual PROMETHEE software. Based on the results, the alternatives of prevention of unsuitable land use changes (A18), vegetation cover development and reclamation (A23) and modification of ground water harvesting (A31) with pure out ranking progress of $\mathrm{p} h i=0.3660,0.1909$ and -0.0887 were selected as the main combating desertification altarnative in the study area, respectively. Therefore, it is suggested that the obtained results and ranking should be considered in projects of controlling and reducing the effects of desertification and rehabilitatyion of degraded lands plans.
\end{abstract}

Keywords: preference, rank, matrix, criteria, model, pirewise comparison, Iran

\section{Introduction}

Management of desert ecosystem is a collection of various management actions which is done for optimal control of desertification phenomena and decline of economic, social and environmental damages. Decision making issues of desert area management are complex issues because of various decision making criteria. There are several ways in order to achieve a specific goal that each of them provides different preferences for different economic, social, environmental, political and institutional issues. These requirements cause the use of Multiple Attribute Decision Making method which its goal is selection of the best answer among the different solutions. So the goal of this study, due to the limitation of inputs, is assessment of de- desertification alternatives in order to achieve the optimal alternatives in the context of sustainable management of desert area. In order to achieve this goal in the context of Multiple Attribute Decision Making models, Preference Ranking Organization Method for Enrichment Evaluation (PROMETHEE) that is one of the most important (Chou et al., 2004) and understandable (Pomerol and Romero, 2000) methods of Multiple Attribute Decision Making for ranking of dedesertification alternatives, was considered. Facility, clarity and stability of results are some of advantages of PROMETHEE method. This method can evaluate a set of alternatives either as a partial ranking or as a complete ranking. Clear impact of each criteria and its weight value on answers, high-performance of algorithms despite the simplicity in this method and its basis that is on the importance of the performance difference between the two answers, are some of Characteristics of this method (Mohaghar and Mostafavi, 2007).

The history of the use of decision making models for optimal alternatives presentation, in the context of desert area management is limited to Grau et al. and Sadeghiravesh et al. researches. Grau used Elimination Et Choice 
Translating Reality (ELECTRE), Analytical Hierarchy Process (AHP) and PROMETHEE models in his research in order to select optimal alternatives for providing an integrated plan for erosion and desertification control (Grau et al, 2010). His study results indicated high- performance of these models in providing optimal alternatives for de- desertification, and the results were the same despite the use of complex methods in each model.

Sadeghiravesh also used AHP (Sadeghiravesh et al, 2010) technique for order preference by similarity to ideal solution (TOPSIS) (Sadeghiravesh et al, 2012) ، Electera (Sadeghiravesh et al, 2014) and fuzzy analytical hierarchy process (Sadeghi ravesh et al, 2015) and prioritized de- desertification alternatives in Khezer Abad region. The results of these studies were identical and also similar to the results of the present study.

Relating to the use of PROMETHEE model, Researches have been done for decision making and ranking in different science. Selection of an appropriate transportation system in an underground mine, (Elevli and Demirci, 2004), Selection of suitable alternatives for optimal utilization of energy (Shirsikar and Patil, 2005), Assessment of famous alternatives in production of energy (Diakoulaki and Karangelis, 2007), The choice of appropriate alternatives for profitable investment in stock market (Albadavi, et al., 2007), Assessment of suitable location for a recycling factory (Queiruga, et al., 2008), Evaluation of potential of alternatives for a construction company (Ginevicius et al., 2010), Choosing a suitable system to dry material (Prvulovic et al, 2011), Selection of appropriate alternatives for profitable investment in stock market (Chen et al., 2011), Selection of suitable alternatives in designing rescuer robots (Taillandier and Stinckwich, 2011), Selection of raw materials supplier (Safari et al, 2012), Selection of a suitable way for machining (Karandea and Chakraborty, 2012) and Choosing the best alternatives for determining the location of storage (Fontana and Cavalcante, 2014) are samples of these researches.

In recent years, also, some researches have been considered in this context in Iran. Selection of project team members (Omidi et al, 2011), Evaluation of innovation condition in southwest Asia countries (Bakhshi et al, 2011) and Assessment of ecological potential of agriculture (Nasiri et al., 2012) are samples of these researches. In all of these studies, researchers used Entropy method, Linmap, Weighted average method, the least squares method and Eigenvector method and assessed weight value of criteria and then prioritized alternatives by the use of PROMETHEE technique (Asgharpour, 1999). Extensive investigations in this study show that PROMETHEE model has not been used either in Iran or other countries for desert area management issues. This paper tries to provide systematic and optimal de-desertification alternatives in a group decision-making model for controlling, reclamation of disturbed lands and avoiding destruction areas at desertification risk

\section{Method}

PROMETHEE model is one of the new out ranking methods of Multiple Attribute Decision Making systems that is used for ranking of alternatives among inconsistent criteria (Behzadian and Pirdashti, 2009). For the first time, this method was introduced by Barns in 1982 at a conference in Laval University in Quebec City (Barns, 1982; Halouani, 2009) and then was developed by Barns and Vincke (Barns and Vincke, 1985; Barns, et al, 1986) and Barns and Mareschal (Brans and Mareschal, 1994; Brans and Mareschal, 2005). The development of this method in different situations created copies that are named as PROMETHEE family and are included PROMETHEE I, II, III, IV, V, VI.

Because the goal of this study is selection of de- desertification optimal alternatives on the basis of a set of effective criteria, PROMETHEE II, with the ability of separated alternatives complete ranking, has been used (Chou et al., 2004). This method is effective and compatible in where numerous alternatives should be assessed based on quantitatively, qualitatively and often contradictory criteria (Albadavi et al, 2007).

This method is simpler than other methods conceptually and practically (Albadavi et al, 2007; Pomerol and Romero, 2000). Also, Software features that are provided for this method as a support, ready appropriate analysis for determiner (Keyser and Peeters, 1996). There is limitation in the use of PROMETHEE technique for compensation of a criteria disadvantage or strong point, so an ideal alternative should gain minorities from all criteria. This means that an alternative can only gain the best rating when it has a comprehensive attitude. So PROMETHEE method is more effective than other methods which use algebraic sum. In addition, PROMETHEE method can use criteria with different scales without needing to match the criteria scales and it defines the distinct six functions commensurate by criteria scale and information, so it is a strong point for determinant in Multiple Attribute Decision Making that usually criteria are measured with different scales. Also when assessing alternatives are not identical, for example one alternative has better function for a special criteria and the other alternative for another criteria, like this study, the use of PROMETHEE is useful like other Multi- criteria methods such as ELECTERA (Soltanmohammad et al, 2008). PROMETHEE 
disadvantage is that there is no approach for weighting criteria and it is assigned to the determinant (Macharis et al, 2007). So at first, weight of criteria should be assessed with Entropy method, weighted average, Linamp, The least squares and Eigenvector method and then alternatives should be prioritized by the use of PROMETHEE technique (Asgharpour, 1999).

In this method for assessing several alternatives, based on some criteria, type of criteria, preference function, preference threshold and indifference threshold, Should be specified. For increasing the PROMETHEE performance, Graphical Analysis for Interactive Assistance technique or GAIA is used. This technique helps determinant about criteria differences and weight of criteria on final results and for this purpose, Visual PROMETHEE software should be used.

Briefly, steps of this method are as follow:

\subsection{Selection of Effective Alternatives and Criteria}

Choosing criteria and alternatives from a lot of proposed criteria and alternatives in de- desertification process could be done either, according to the experience of the expert, information sources and field studies or by the use of Delphi technique and preparation of questionnaire then asking experts familiar with the study area to express effective alternatives and criteria and also score them form 0 to 9 . Finally by gaining the average of all criteria or alternatives any alternative with the mean value less than $7(\bar{X}<7)$, would be removed but alternatives with the mean value more or equal to $7(\bar{X} \geq 7$ ) would be used (Azar and Rajabzadeh, 2002; Azar and Memariani, 2003).

\subsection{Calculate Local Priority of Criteria and Alternatives and Establish Group Pirewise Comparisons Matrix}

In continuation, to achieve local priority, a second questionnaire entitled "pirewise comparisons questionnaire" was designed and Experts were asked to conduct pirewise comparison on obtained results of first questionnaire regarding the nine-point Saaty's scale (Table1) based on importance to goal and priority to each criteria respectively. After forming pairwise comparisons matrix of each expert about criteria importance and alternatives priority (Table2), by the use of geometric mean and assumption of uniform expert's opinion, pirewise comparisons of each expert were composed according to Eq. 1; and pirewise comparisons were formed regarding to group (Azar and Rajabzadeh, 2002, Ghodsipour, 2002).

$$
\bar{a}_{i j}=\left(\pi_{\mathrm{k}=1}^{\mathrm{N}} \mathrm{a}_{\mathrm{ij}}{ }^{\mathrm{k}}\right)^{\frac{1}{\mathrm{~N}}}
$$

Table1. Importance and priority degree of nine-point Satty's scale (Azar \& Rajabzadeh, 2002)

\begin{tabular}{lll}
\hline Score & Importance Degree & Priority Degree in Pirewise Comparison \\
\hline 1 & Non-importance & Equal \\
2 & Very low & Equal-Moderately \\
3 & Low & Moderately \\
4 & Relatively low & Moderately - Strongly \\
5 & Medium & Strongly \\
6 & Relatively high & Strongly-Very strongly \\
7 & High & Very strongly \\
8 & Very high & Very strongly-Extremely \\
9 & Excellent & Extremely \\
$1 / 2,1 / 3,1 / 4, \ldots, 1 / 9$ & Mutual Values \\
\hline
\end{tabular}

Table2. pirewise comparaisons matrix (Azar \& Rajabzadeh, 2002)

$$
\mathrm{A}=\left|\begin{array}{cccc}
\mathrm{a}_{11} & \mathrm{a}_{12} & \ldots \ldots \ldots & \mathrm{a}_{1 \mathrm{n}} \\
\mathrm{a}_{21} & \mathrm{a}_{22} & \ldots \ldots \ldots & \mathrm{a}_{2 \mathrm{n}} \\
: & : & : & : \\
\mathrm{a}_{\mathrm{m} 1} & \mathrm{a}_{\mathrm{m} 2} & \ldots \ldots \ldots & \mathrm{a}_{\mathrm{mn}}
\end{array}\right| \quad \begin{gathered}
\mathrm{A}=\left[\mathrm{a}_{\mathrm{ij}}{ }^{\dagger}\right], \mathrm{i}=1,2, \ldots . \mathrm{m} \\
\mathrm{a}=\text { preference of } \mathrm{i} \text { criteria to } \mathrm{j} \text { criteria }
\end{gathered}
$$




\subsection{Compute the Priorities Based on Group Pirewise of Comparisons Tables}

At this stage, the numbers of group pirewise comparisons matrix (values of criteria importance and alternatives priority to each criterion) were calculated based on weighted average or average of each level of normalized matrix (Fig. 3 and 4) after normalization by using Eq. 2.

$$
\overline{r_{i j}}=\frac{\overline{a_{i j}}}{\sum_{i=1} \overline{a_{i j}}}
$$

\subsection{Formation of Normalized Decision Matrix (NDM)}

The Weighs of criteria importance $\left(\mathrm{W}_{\mathrm{j}}\right)$ and alternatives priority $\left(\mathrm{P}_{\mathrm{ij}}\right)$ were entered according to decision matrix (Table3).

Table3. Normalized Decision Matrix (NDM)

\begin{tabular}{cccccc}
\hline Alt & \multicolumn{5}{c}{ Criterion } \\
\cline { 2 - 6 } & $\mathrm{C}_{1}$ & $\mathrm{C}_{2}$ & $\mathrm{C}_{3}$ & ------- & $\mathrm{C}_{\mathrm{n}}$ \\
& $\mathrm{W}_{1}$ & $\mathrm{~W}_{2}$ & $\mathrm{~W}_{3}$ & -------- & $\mathrm{W}_{\mathrm{n}}$ \\
$\mathrm{A}_{1}$ & $\mathrm{P}_{11}$ & $\mathrm{P}_{12}$ & $\mathrm{P}_{13}$ & ------ & $\mathrm{P}_{1 \mathrm{n}}$ \\
$\mathrm{A}_{2}$ & $\mathrm{P}_{21}$ & $\mathrm{P}_{22}$ & $\mathrm{P}_{23}$ & -------- & $\mathrm{P}_{2 \mathrm{n}}$ \\
$\vdots$ & $:$ & $\vdots$ & $\vdots$ & $:$ & $\vdots$ \\
$\mathrm{A}_{\mathrm{m}}$ & $\mathrm{P}_{\mathrm{m} 1}$ & $\mathrm{P}_{\mathrm{m} 2}$ & $\mathrm{P}_{\mathrm{m} 3}$ & --------- & $\mathrm{P}_{\mathrm{mn}}$ \\
\hline
\end{tabular}

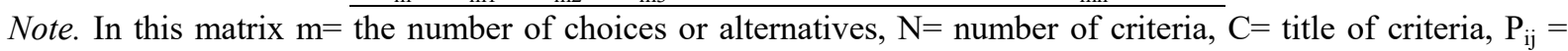
weight value that each alternative gains in relation to related criteria, $\mathrm{W}_{\mathrm{j}=}$ Weight value that each criteria gains in relation to the goal.

\subsection{Calculating the Difference Between Pirewise Sizes of Alternatives in Each Criterion (Dj) and Forming Table of Sizes Difference}

The difference between pirewise sizes of alternatives (i) in each criterion (j) was calculated according to Eq. 3 (Table 4).

$$
d_{j}(a, b)=P_{a j}-P_{b j}
$$

$d_{j}(a, b)=$ The difference between sizes of alternatives $\mathrm{a}$ and $\mathrm{b}$ in different criteria

$P_{a j}=$ Alternative a priority based on each criterion

$P_{b j}=$ Alternative $\mathrm{b}$ priority based on each criterion

Table 4. The difference between pirewise sizes of alternatives in each criterion

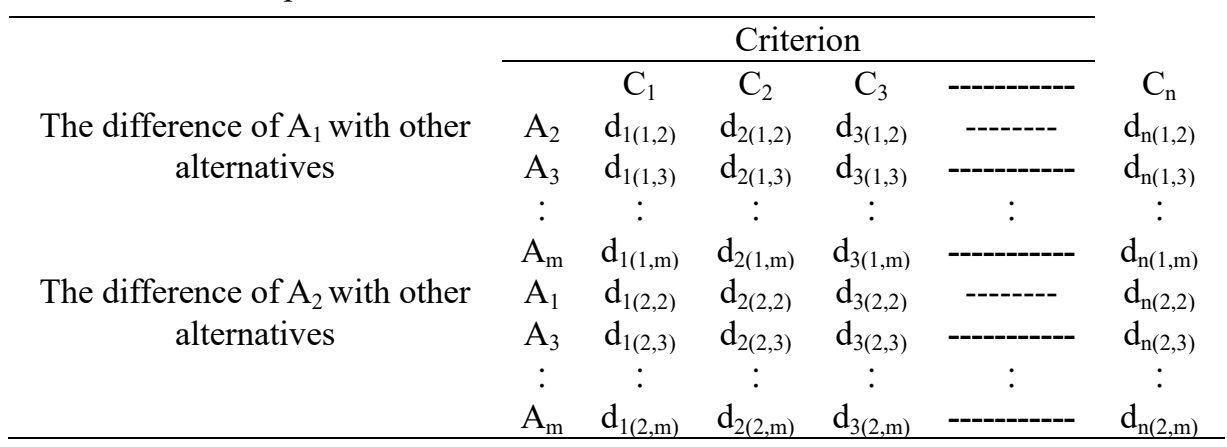

Note. $\mathrm{m}=$ the number of alternatives , $\mathrm{n}=$ the number of criteria, $\mathrm{C}=$ title of criteria, $\mathrm{d}_{\mathrm{ij}=}$ the difference between pirewise sizes of alternatives in each criterion 


\subsection{Calculating Alternatives Preference Function $\left(P_{j}\right)$ and Forming Table of Preference Function}

Preference functions exchange the difference between two alternatives, for a specific criterion, to a degree of preference that varies from 0 to 1 . Determiner should choose a preference function for each criterion. So many preference functions can be defined in this case but usually these six preference functions consist of line function, Gaussian function, u-shaped function, v-shaped function, flat function and normal function are used (Barns et al, 1986).

Preference functions have been shown in figure1. In each of these functions two characteristics of following characteristics should be setup.

These characteristics are as follow:

1. Indifference threshold q: the largest negligible deviation that is considered in criterion.

2. Preference threshold $\mathrm{p}$ : the smallest deviation that is considered for determining full preference by decision makers. Indifference threshold and preference threshold are respectively small and large amounts according to measurement scale.

3. Gaussian threshold s: the turning point of preference threshold is Gaussian. Amount of Gaussian threshold usually is considered between $\mathrm{p}$ and $\mathrm{q}$.

Preference function or alternatives preference (i) in each criterion (j) was calculated according to Eq.4 and in regard to preference functions.

$$
P_{j}(a, b)=P\left[d_{j}(a, b)\right]
$$

$P_{j}(a, b)=$ Preference amount of alternatives $\mathrm{a}$ and $\mathrm{b}$ in different criteria

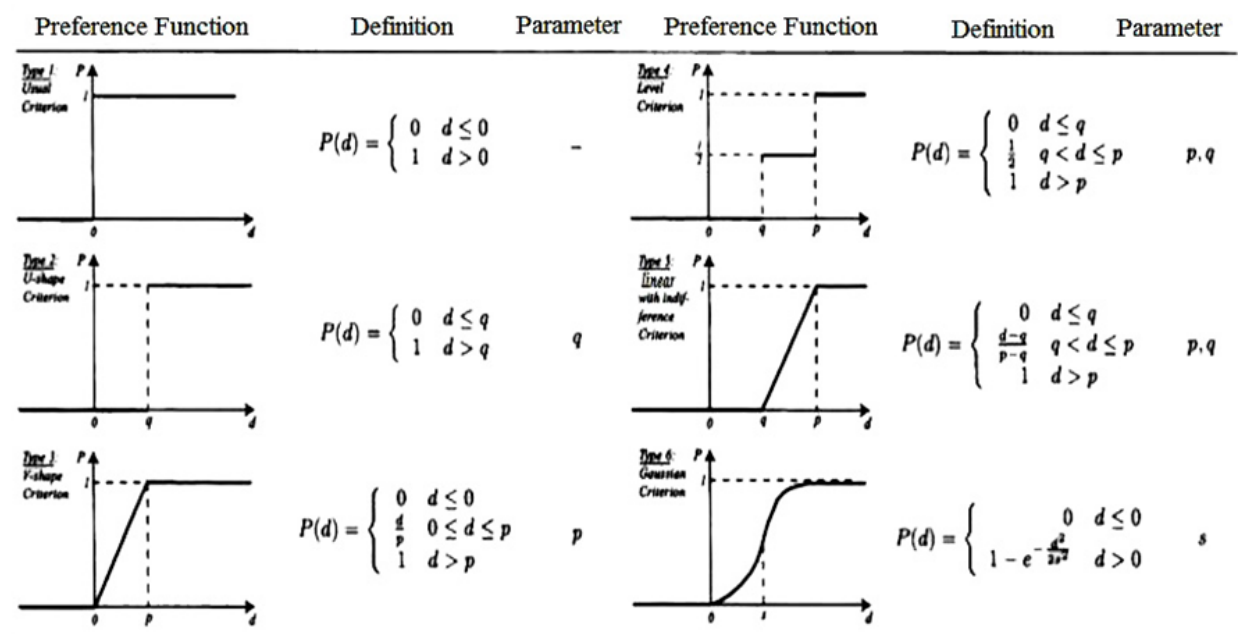

Figure1. The six preference functions (Brans et al., 1986)

Table5. Alternatives pirewise preference in each criterion

\begin{tabular}{ccccccc}
\hline & \multicolumn{7}{c}{ Criterion } \\
\hline & $\mathrm{A}_{2}$ & $\mathrm{P}_{1(1,2)}$ & $\mathrm{C}_{2}$ & $\mathrm{C}_{2}$ & ---------- & $\mathrm{C}_{\mathrm{n}}$ \\
Preference amount of $\mathrm{A}_{1}$ with & $\mathrm{P}_{3(1,2)}$ & ------- & $\mathrm{P}_{\mathrm{n}(1,2)}$ \\
other alternatives & $\mathrm{A}_{3}$ & $\mathrm{P}_{1(1,3)}$ & $\mathrm{P}_{2(1,3)}$ & $\mathrm{P}_{3(1,3)}$ & -------- & $\mathrm{P}_{\mathrm{n}(1,3)}$ \\
& $:$ & $:$ & $:$ & $:$ & $:$ & $:$ \\
& $\mathrm{A}_{\mathrm{m}}$ & $\mathrm{P}_{1(1, \mathrm{~m})}$ & $\mathrm{P}_{2(1, \mathrm{~m})}$ & $\mathrm{P}_{3(1, \mathrm{~m})}$ & --------- & $\mathrm{P}_{\mathrm{n}(1, \mathrm{~m})}$ \\
& $\mathrm{A}_{1}$ & $\mathrm{P}_{1(2,2)}$ & $\mathrm{P}_{2(2,2)}$ & $\mathrm{P}_{3(2,2)}$ & ------- & $\mathrm{P}_{\mathrm{n}(2,2)}$ \\
Preference amount of $\mathrm{A}_{2}$ with & $\mathrm{A}_{3}$ & $\mathrm{P}_{1(2,3)}$ & $\mathrm{P}_{2(2,3)}$ & $\mathrm{P}_{3(2,3)}$ & -------- & $\mathrm{P}_{\mathrm{n}(2,3)}$ \\
other alternatives & $:$ & $:$ & $:$ & $:$ & $:$ & $:$ \\
& $\mathrm{A}_{\mathrm{m}}$ & $\mathrm{P}_{1(2, \mathrm{~m})}$ & $\mathrm{P}_{2(2, \mathrm{~m})}$ & $\mathrm{P}_{3(2, \mathrm{~m})}$ & -------- & $\mathrm{P}_{\mathrm{n}(2, \mathrm{~m})}$ \\
\hline
\end{tabular}

Note. $\mathrm{m}=$ number of alternatives, $\mathrm{n}=$ number of criteria, $\mathrm{C}=$ title of criteria, $\mathrm{P}_{\mathrm{ij}=}=$ preference of alternatives pirewise sizes in each criterion 
2.7 Estimating Weighted Sum of Alternatives Priority Relative to Each Other and Forming Table of Alternatives Priority

Weighted sum of alternatives priority relative to each other was calculated based on table 5 and according to Eq.5.

$$
\left\{\begin{array}{l}
\pi(a, b)=\sum_{j=1}^{k} P_{j}(a, b) W_{j} \\
\pi(b, a)=\sum_{j=1}^{k} P_{j}(b, a) W_{j}
\end{array}\right.
$$

$\pi(a, b)=$ Weighted sum of alternative a priority relative to $\mathrm{b}$

$\pi(b, a)=$ Weighted sum of alternative $\mathrm{b}$ priority relative to a

$\mathrm{W}_{\mathrm{j}}=$ Weights of criteria

Table6. Alternatives priority based on total criteria

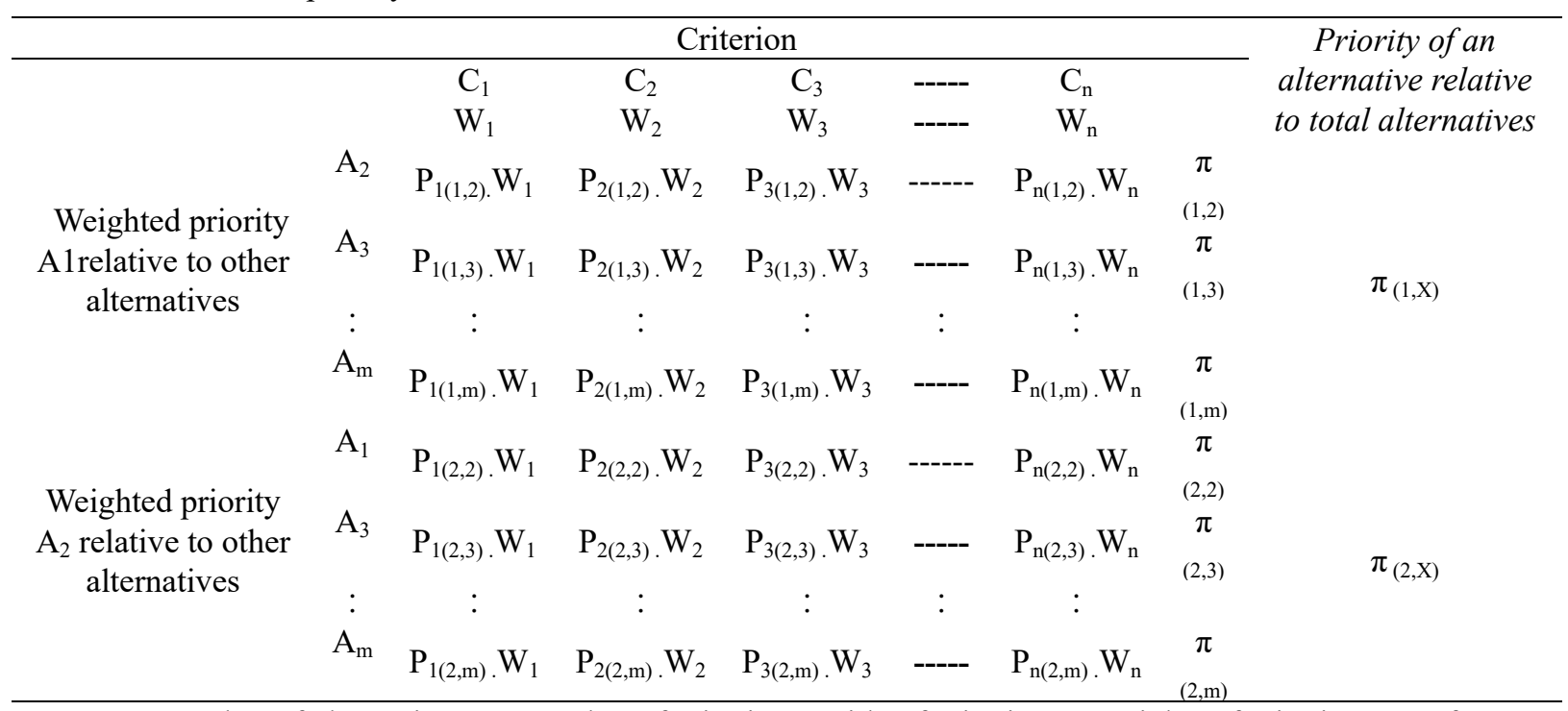

Note. $\mathrm{m}=$ number of alternatives, $\mathrm{n}=$ number of criteria, $\mathrm{C}=$ title of criteria, $\mathrm{w}=$ weights of criteria, $\mathrm{P}_{\mathrm{ij}}=$ preference of alternatives pirewise sizes in each criterion

Finally priority of each alternative (alternative a) relative to total alternatives was calculated according to Eq. 6 (Table6)

$$
\pi(\mathrm{a}, \mathrm{x})=\sum^{\mathrm{m}} \pi_{\mathrm{i}}(\mathrm{a}, \mathrm{i})
$$

2.8 Calculating Positive out Ranking Current and Negative oi $\bar{i}^{2}$ Ranking Current of Each Alternative Relative to Other Alternatives

After calculating priority of each alternative relative to total alternatives, positive out ranking current and negative out ranking current of each alternative was calculated according to Eq.7 and Eq.8. Positive out ranking current shows an alternative preference like a relative to other alternatives. The higher value of it shows that this alternative would be better.

$$
\varphi^{+}(\mathrm{a})=\frac{1}{n-1} \sum_{x \in A} \pi(a, x)
$$

$\mathrm{n}=$ number of alternatives

Negative out ranking current shows other alternatives preference relative to alternative a. The lower value of it 
shows that this alternative would be better.

$$
\varphi^{-}(\mathrm{a})=\frac{1}{n-1} \sum_{x \in A} \pi(a, x)
$$

$\mathrm{n}=$ number of alternatives

\subsection{Alternatives ranking}

In order to rank alternatives completely, PROMETHEE II was used. For determining final priority of alternatives, net out ranking current of each alternative that was obtained from Eq.9, was used.

$$
\phi(\mathrm{a})=\phi^{+}(\mathrm{a})-\phi^{-}(\mathrm{a})
$$

$\varphi(\mathrm{a})=$ Net out ranking current of alternative a preference

So, the better net out ranking current of an alternative, the better that alternative (Eq.10, 11).

$P^{I I}=$ Sign of preference

$$
\left.a P^{I I} b \text { iff } \varphi(\mathrm{a})\right\rangle \varphi(\mathrm{b})
$$

$a P^{I I} b=$ Alternative $\mathrm{a}$ is preferred relative to alternative $\mathrm{b}$ because of alternative $\mathrm{b}$ limitation

$I^{I I}=$ Sign of indifference

$$
a I^{I I} b \text { iff } \varphi(\mathrm{a})=\varphi(\mathrm{b})
$$

$a I^{I I} b=$ Alternative a and alternative $\mathrm{b}$ are equally preferred

In this method all alternatives are comparable.

For calculating output and input current and also preference net current in order to estimate alternatives preference, Visual PROMETHEE software was used.

\section{Results}

\subsection{Selection of Important Criteria and Preferred Alternative According to Group and Design Hierarchical} Decision Structure

In order to achieve important criteria and preferred alternative among several criteria and alternatives, a questionnaire was prepared in two parts according to the Delphi method. Finally, by gaining the average of given scores to each criteria and alternative, any of them with the mean value less than 7 were removed and others were used for designing hierarchical decision structure (Figure 2).

\begin{tabular}{llll}
\hline & degree & criterion \\
\hline & $\mathbf{3 3 . 3}$ & $\mathrm{C}_{7}$ \\
\hline & $\mathbf{3 1 . 1}$ & $\mathrm{C}_{16}$ \\
& & $\mathbf{1 5 . 7}$ & $\mathrm{C}_{6}$ \\
\hline & & $\mathbf{1 1}$ & $\mathrm{C}_{5}$ \\
\hline & & $\mathbf{8 . 9}$ & $\mathrm{C}_{2}$ \\
\hline & & & \\
\hline
\end{tabular}

Figure 2. Hierarchical decision structure to select optimal de-desertification alternatives in Kezr Abad region

\subsection{Calculate Relative Weight of Criteria and Alternatives and Format Group Decision Matrix (DM)}

In order to calculate relative weight of criteria and alternatives or their priority, pirewise comparisons questionnaire was prepared and distributed among experts. Then by combining experts' opinions and by the use of geometric mean, group pirewise comparisons matrix of criteria importance relative to the goal and alternatives priority relative to all criteria was formed. Here, only criteria importance matrix is presented (Table7). 
Table7. Group pirewise comparisons matrix of criteria importance relative to the goal of "offering optimal de-desertification alternatives in Kherz Abad region"

\begin{tabular}{cccccc}
\hline criterion & $\mathrm{C}_{16}$ & $\mathrm{C}_{6}$ & & $\mathrm{C}_{5}$ & \\
\hline $\mathrm{C}_{7}$ & $1 / 2$ & $2 / 5$ & $2 / 5$ & $\mathrm{C}_{2}$ \\
$\mathrm{C}_{16}$ & & $2 / 3$ & $3 / 1$ & $3 / 4$ & $3 / 1$ \\
$\mathrm{C}_{6}$ & & & $1 / 7$ & 2 \\
$\mathrm{C}_{5}$ & & & & $1 / 3$ \\
\hline
\end{tabular}

In continuation, matrix values of criteria importance and alternatives priorities were entered EC software based on each criterion, and importance and priority of de-desertification criteria and alternatives were obtained according to group in the study area as bar graphs Based on percentage using normalization and weighted mean (Figure 3).

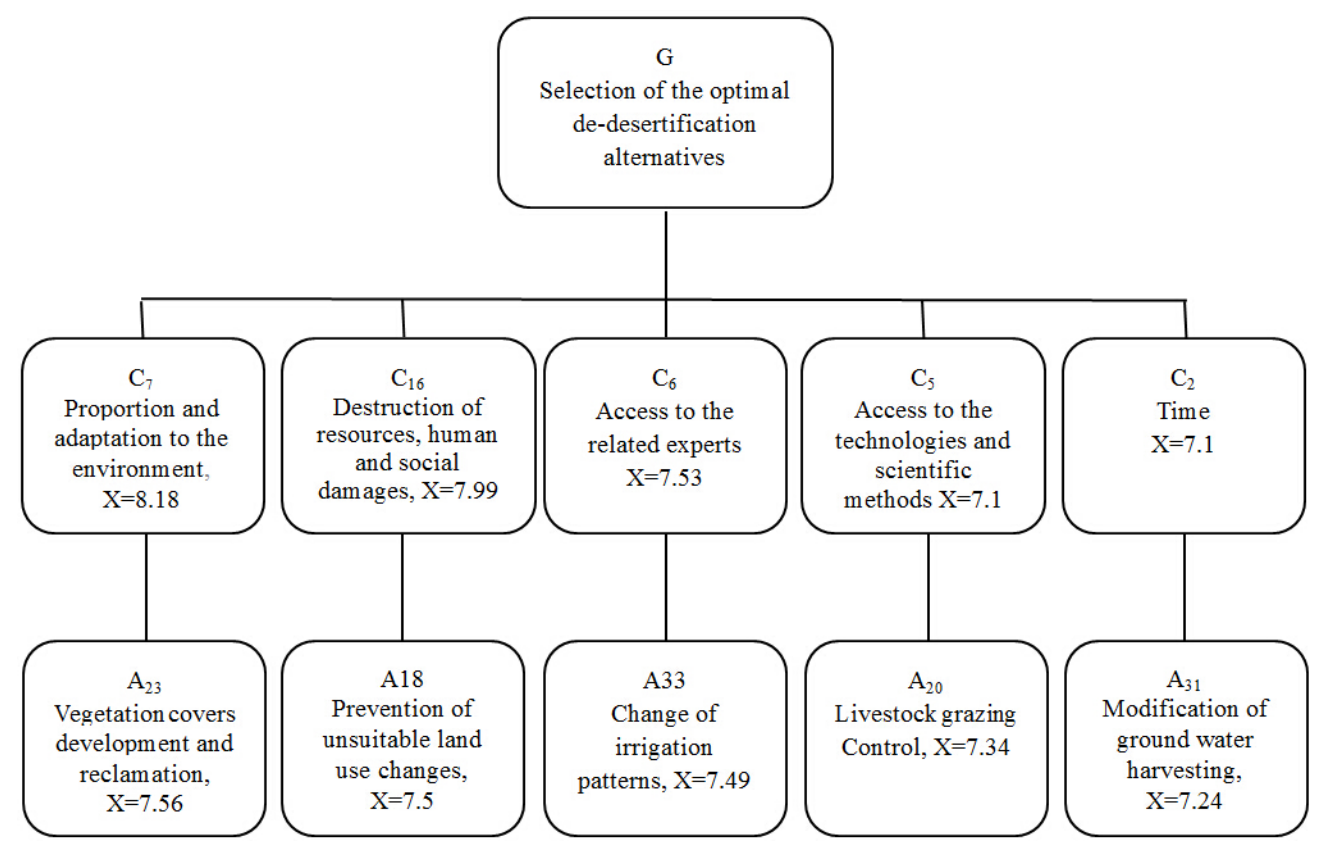

Figure 3. Comparison of proposed criteria importance in order to achieve the goal

Considering these graphs it is observed that the alternatives are different based on each criterion. Therefore, decision making matrix of optimal de-desertification alternatives according to the group (Table8) was formed to select final alternatives and classification of their priorities, in general framework of multiple attribute decision making methods (Table3).

Table 8. Decision matrix of optimal de-desertification alternatives according to group

\begin{tabular}{cccccc}
\hline $\begin{array}{c}\text { Criteria importance (C) } \\
\text { Alternatives priority (A) }\end{array}$ & $\mathrm{C}_{2}$ & $\mathrm{C}_{5}$ & $\mathrm{C}_{6}$ & $\mathrm{C}_{16}$ & $\mathrm{C}_{7}$ \\
$\boldsymbol{\nabla}$ & 0.0892 & 0.1095 & 0.1576 & 0.3074 & 0.3365 \\
\hline $\mathrm{A}_{23}$ & 0.2509 & 0.2387 & 0.2488 & 0.1805 & 0.2257 \\
$\mathrm{~A}_{18}$ & 0.1960 & 0.1635 & 0.1983 & 0.2383 & 0.2643 \\
$\mathrm{~A}_{33}$ & 0.1620 & 0.2565 & 0.2093 & 0.1510 & 0.1599 \\
$\mathrm{~A}_{20}$ & 0.2229 & 0.1762 & 0.1608 & 0.2209 & 0.1582 \\
$\mathrm{~A}_{31}$ & 0.1682 & 0.1633 & 0.1826 & 0.2092 & 0.1918 \\
\hline
\end{tabular}

\subsection{Determination of Positive, Negative and Net Currents of Alternatives and Final Prioritizing of Criteria}

In order to achieve final ranking of alternatives, after determination of criteria preference and alternatives 
priority in the framework of normalized decision making matrix (table.8) data of this table were entered Visual PROMETHEE software (Fig4). In terms of preference function, Barns and Vincke (1985) emphasized to use Gaussian function for practical application especially continuous data. So, in this study, for criteria of time, Gaussian preference function was used and s threshold was calculated according to Eq.12.

$$
S=\left(\bar{X}-X_{\min }\right)+2 \delta
$$

$\bar{X}=$ Average of total alternatives in each criterion

$X_{\min }=$ The minimum amount of total alternatives in each criterion

$\delta=$ Standard deviation of total alternatives in each criterion

Also V-shaped function was used for other criteria. Amount of $\mathrm{P}$ threshold for this preference function was calculated based on the difference between maximum and minimum amount of alternatives. Then data of table 9 were entered Visual PROMETHEE software and PROMETHEE Table (9) key was selected and input, output and net currents of each alternative were calculated relative to other alternatives (Fig5).

Table9. Necessary characteristics for criteria

\begin{tabular}{cccccc}
\hline criteria & Effect type & Preference function & $\mathrm{S}$ & $\mathrm{P}$ & Weight of criteria (\%) \\
\hline $\mathrm{C}_{7}$ & Maximize & V-shape & - & 0.1061 & 0.3365 \\
$\mathrm{C}_{16}$ & Maximize & V-shape & - & 0.0873 & 0.3074 \\
$\mathrm{C}_{6}$ & Maximize & V-shape & - & 0.088 & 0.1576 \\
$\mathrm{C}_{5}$ & Maximize & V-shape & - & 0.0932 & 0.1095 \\
$\mathrm{C}_{2}$ & Maximize & Gaussian & 0.154955 & - & 0.0892 \\
\hline
\end{tabular}

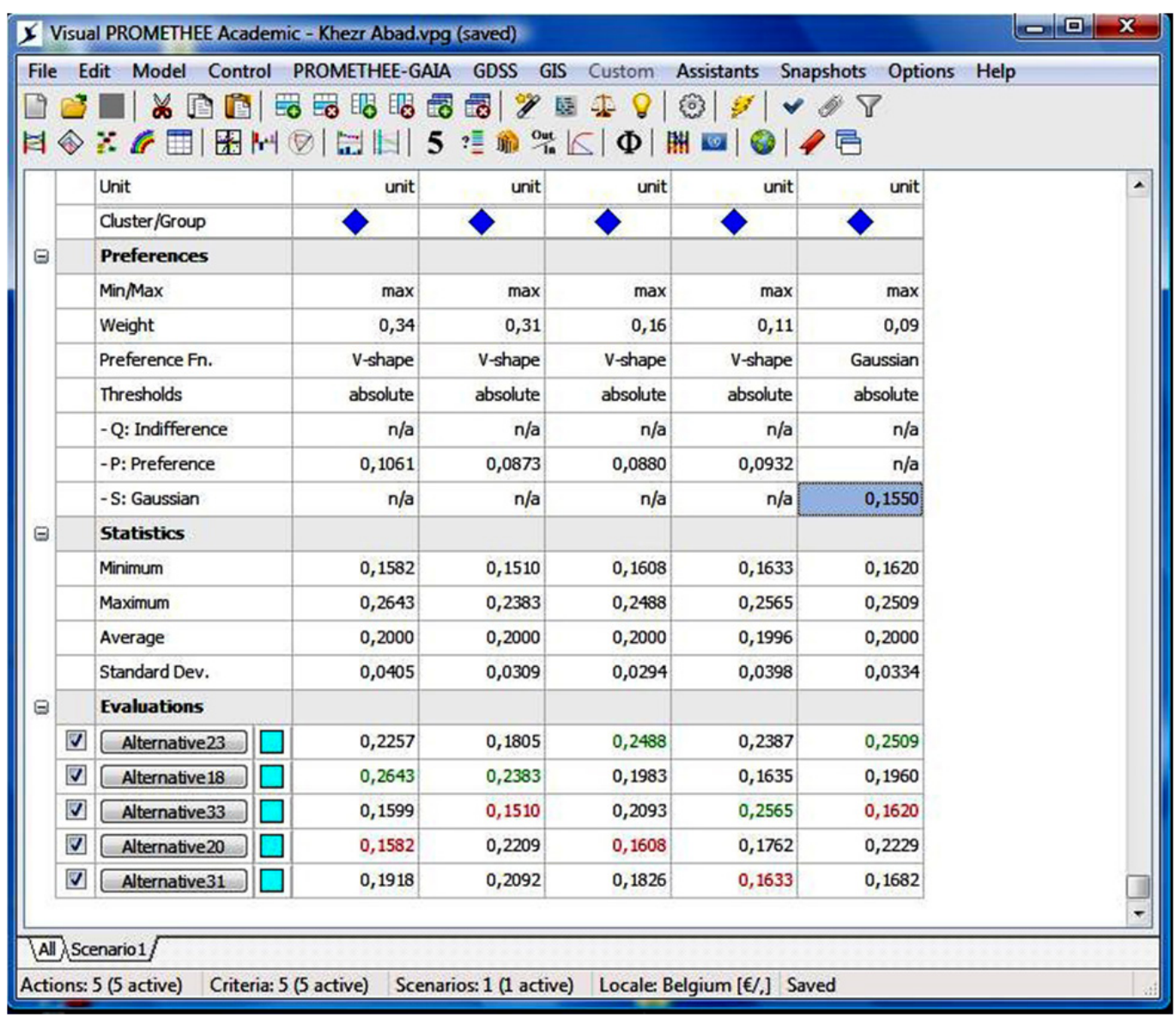

Figure 4. Decision matrix data in Visual PROMETHEE 


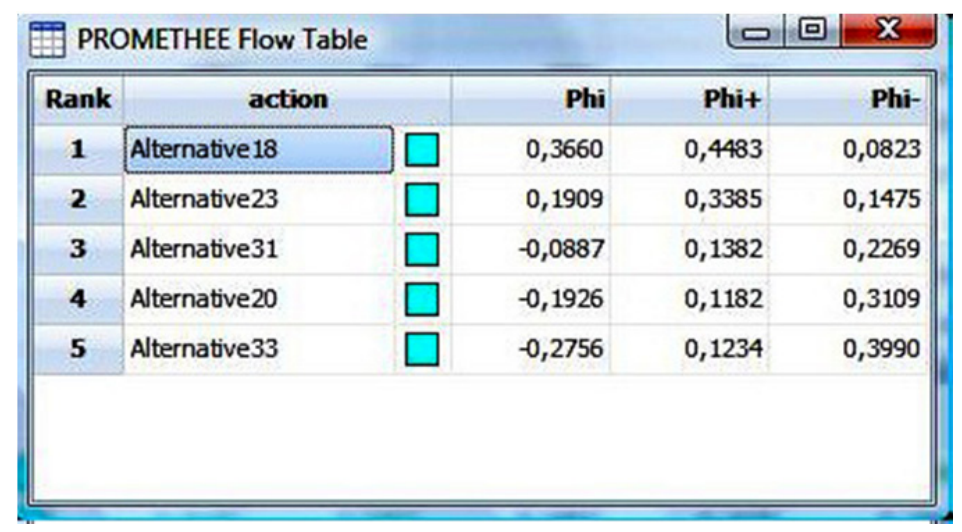

Figure 5. postitive, negative and net out ranking currents of de-desertification alternatives in study area

Finally in order to analyze the results better, GAIA graph was used in Visual PROMETHEE software (Fig.6). This graph is a powerful tool for analyzing multivariate issues that indicates criteria preference, alternatives priority, quality of each alternative and opposite and positive aspects of criteria clearly.

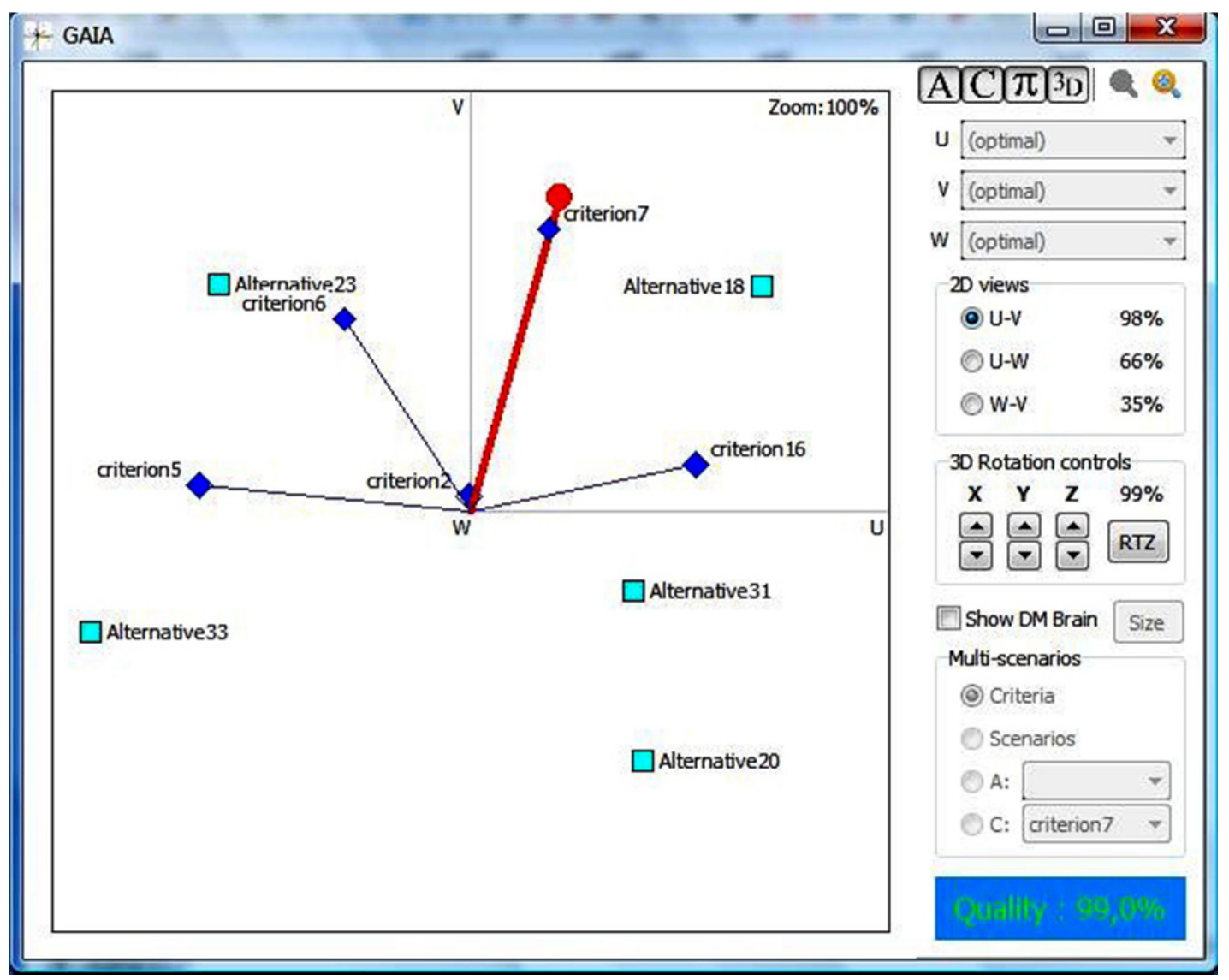

Figure 6. GAIA graph for ranking of de-desertification criteria and alternatives

Criteria $\mathrm{C}_{7}, \mathrm{C}_{16}, \mathrm{C}_{6}, \mathrm{C}_{5}, \mathrm{C}_{2}$ were respectively preferred according to figure and suggested alternatives were different according to each criterion. For example in relation to criteria $\mathrm{C}_{7}, \mathrm{C}_{16}$ alternative $\mathrm{A}_{18}$ was preferred and in relation to criteria $\mathrm{C}_{5}$ alternative $\mathrm{A}_{33}$ was preferred. So Promethee decision axis ( $\boldsymbol{\pi}$ axis) was obtained in order to select alternatives based on total criteria. The Promethee decision axis indicated priority of alternative $A_{18}$ in order to achieve the goal. Alternatives $\mathrm{A}_{23}, \mathrm{~A}_{31}, \mathrm{~A}_{20}$ and $\mathrm{A}_{33}$ were the next order respectively (Fig6, 7). According to figure 7 , obtained results are reliable with $99 \%$ accuracy. 


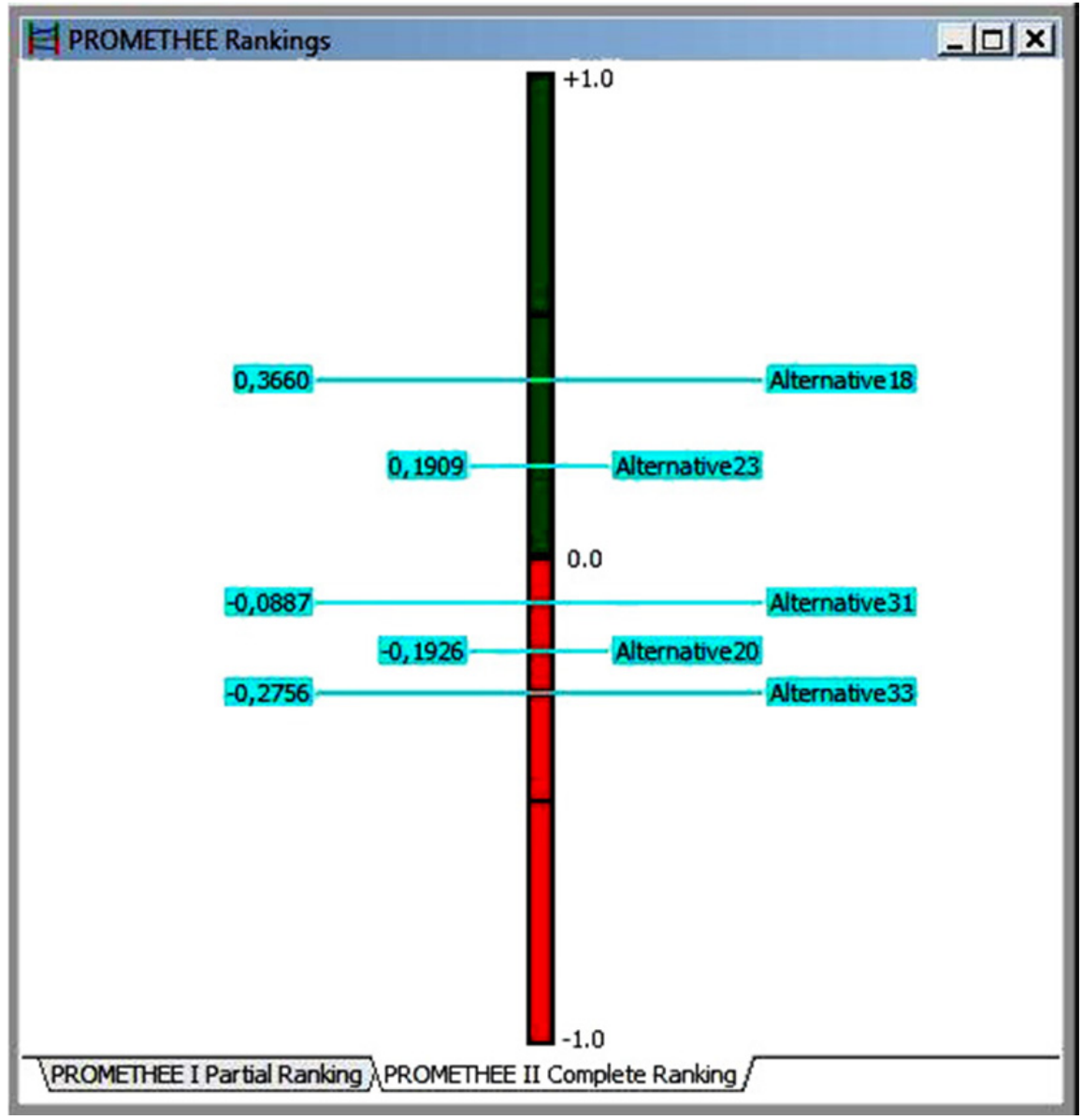

Figure 7. complete ranking of alternatives based on PROMETHEE II

\section{Discussion}

In this study a new method was represented in order to rank alternatives priority for combating desertification process. Obtained results of PROMETHEE method for final prioritizing of alternatives emphasize on obtained results of AHP ‘TOPSISs 'ELECTERE and WSM for prioritizing alternatives and alternatives A18, A23, A31 were placed in first, second and third order respectively.

PROMETHEE method, like above mentioned method, has the limitation of ignoring determinants fuzzy judgment. Also some criteria have unknown structure or qualitative structure and cannot be measured accurately. In this situation, in order to achieve evaluation matrix, we can use fuzzy numbers. So the mentioned prioritizing method can be developed by the use of fuzzy numbers. Also software features that are provided as a support for this method, prepare appropriate analysis for determinant. The results of this method are closer to reality because there is a comprehensive development attitude in it.

Based on the results, the alternatives of prevention of unsuitable land use changes (A18), vegetation cover development and reclamation (A23) and modification of ground water harvesting (A31) with pure out ranking progress of phi $=0.3660,0.1909$ and -0.0887 were selected as the main de-desertification altarnative in the study area, respectively. So by the use of these alternatives in de-desertification projects, we can prevent desertification phenomenon in this area and do something for reclamation of degraded land.

In study area, land use changes are developing strongly because of population grow, unemployment, industrial and urbanization grow. Usually land use changes has occurred as conversion of pasture land to farm and garden because of deep and semi-deep wells development, conversion of garden to agriculture land on the effect of successive droughts and conversion of pasture land to urban and industrial land because of industrial and urbanization grow in recent years.

Pasture types density is 6 to 15 percent that is influenced by human actions strongly, and 40 to 50 percent of vegetation cover is destroyed because of cutting to compile livestock, fuel and building materials. 
Irrigation for agriculture land is usually flood irrigation and basin irrigation, so over 50 percent of water is wasted and irrigation efficiency is calculated less than 40 percent in the farm.

So following executive suggestions are recommended in the framework of discussed macro alternatives:

Land use planning and estimating the ecological potential in national, regional and local levels and land use conformity with land potential.

Preventing inappropriate conversion of poor pasture land to garden with low efficiency and high potential for degradation and erosion.

Preventing development of industrial infrastructure in sensitive lands of desert areas and marginal areas.

The use of resistant and pasture species and modern irrigation systems for vegetation cover development and reclamation.

Prevention of Tamarix habitat destruction and trying for their reclamation

Observing the balance between number of livestock and pasture capacity

Conformity between livestock type and pasture condition should be considered and the number of goats should be reduced in poor pastures, because these animals increase pastures destruction, potentially.

It is recommended that de-desertification projects in the study area be focused on these alternatives to get better and suitable results, avoid investment wasting and increase control, reclamation and reconstruction project efficiency.

\section{References}

Albadavi, A., Chaharsooghi, S. K., \& Esfahanipour, A. (2007). Decision making in stock trading: An application of PROMETHEE. European Journal of Operational Research, 177, 673-683. http://dx.doi.10.1016/j.ejor.2005.11.022

Asgharpour, M. J. (1999). Multiple criteria decision making, University of Tehran, Tehran, p. 397.

Azar, A., \& Memariani, A. (2003), AHP new technique for group decision making, Journal of Knowledge Management, 28, 22-32.

Azar, A., \& Rajabzadeh, A. (2002). Applied decision making (1st ed., p. 185), Tehran: Negahe Danesh.

Bakhshi, M., Panahi, R., Mollaei, Z., Kazemi, H., \& Mohammadi, D. (2011). Evaluation of Innovation in South West Asia Countries and Determine of Iran'S Position: Application of PROMETHEE, Journal of Science and Technology Policy, 3, 19-33.

Barns, J. P. (1982). Lingenierie de la decision. Elaboration dinstruments daide a la decision. Method PROMETHEE. In: Nadeau, R., Landry, M. (Eds.), Laide a la Decision: Nature, Instrument set Perspectives Davenir. Presses de Universite Laval, Quebec, Canada, 183-214.

Behzadian, M., \& Pirdashti, M. (2009). Selection of the Best Module Design for Ultrafiltration (UF)Membrane in Dairy Industry: An Application of AHP and PROMETHEE. International Journal of Engineering, 3, 126-142.

Brans, J. P., \& Mareschal, B. (1994). The PROMCALC and GAIA Decision Support System for Multicriteria Decision Aid, Decision Support Systems, 12, 297-310. http://dx.doi.10.1016/0167-9236(94)90048-5

Brans, J. P., \& Mareschal, B. (2005). Multiple Criteria Decision Analysis: State of the Art Surveys, Chapter 5: ROMETHEE METHODS, Springer, New York, 195.

Brans, J. P., \& Vincke, Ph. (1985). A Preference ranking Organization Method, The PROMETHEE Method for Multiple Criteria Decision-Making, Management Science, 31, 647-656.

Brans, J. P., Vincke, Ph., \& Mareschal, B. (1986). How to select and how to rank projects: The PROMETHEE method, European Journal Operational Research, 4, 138-228.http://dx.doi.10.1016/0377-2217(86)90044-5

Chen, C. T., Hung, W. Z., Cheng, H. L. (2011). Applying linguistic PROMETHEE method in investment portfolio decision making, International Journal of Electronic Business Management, 9(2), 139-148.

Chou, T. Y., Lin, W. T., Lin, C. Y., Chou, W. C., \& Huang, P. H. (2004). Application of the PROMETHEE technique to determine depression outlet location and flow direction in DEM, Journal of Hydrology, 287, $49-61$.

Diakoulaki, D., \& Karangelis, F. (2007). Multi-criteria decision analysis and cost-benefit analysis ofalternative 
scenarios for the power generation sector in Greece. Renewable and Sustainable Energy Reviews, 11, 716727. http://dx.doi.10.1016/j.rser.2005.06.007

Elevli, B., \& Demirci, A. (2004). Multicriteria choice of ore transport system for an underground mine: Application of PROMETHEE methods. Journal of the South African Institute of Mining and Metallurgy, 104, 251-256.

Fontana, M. E., \& Cavalcante, C. A. V. (2014). Use of PROMETHEE method to determine the best alternative for warehouse storage location assignment, The International Journal of Advanced Manufacturing Technology, 70, 1615-1624. http://dx.doi.10.1007/s00170-013-5405-z

Ghodsipour, S. A. H. (2002). Analytical Hierarchy Process (AHP), Amirkabir University, Tehran, 220 p.

Ginevicius, R., Podvezko, V., \& Novotny, M. (2010). The use of PROMETHEE method for evaluating the strategic potential of construction enterprises. The 10th International Conference of modern building materials, structures and techniques, Vilnius, Lithuania, 19- 21 May, 407- 413.

Grau, J. B., Anton, J. M., Tarquis, A. M., Colombo, F., Rios, L., \& Cisneros, J. M. (2010). Mathematical model to select the optimal alternative for an integral plan to desertification and erosion control for the Chaco Area in Salta Province (Argentine), Journal of Biogeosciences Discuss, 7, 2601-2630. http://dx.doi.10.5194/bg-7-3421-2010

Halouani, N., Chabchoub, H., \& Martenez, J.M. (2009). PROMETHEE-MD-2T method for project selection. European Journal of Operational Research, 195, 841-849. http://dx.doi.10.1016/j.ejor.2007.11.016

Karandea, P \& Chakraborty, S. (2012). Application of PROMETHEE-GAIA method for non-traditional machining processes selection, Management Science Letters, 2, 2049-2060. http://dx.doi.10.5267/j.msl.2012.06.015

Keyser, W. D., \& Peeters, P. (1996). Theory and Methodology a note on the use of PROMETHEE multicriteria methods, European Journal of Operational Research, 89, 457-461.

Macharis, C., Springael, J., Brucker, K. D., \& Verbeke, A. (2007). PROMETHEE and AHP: The design of operational synergies in multicriteria analysis, Strengthening PROMETHEE with ideas of AHP. European Journal of Operational Research, 153, 307-317.

Mohaghar, A., \& Mostafavi, A. (2007). Designing a Model for Selecting Project Team Based on Fuzzy Approach, Management Research in Iran, 11, 207-232. http://dx.doi.10.1016/S0377-2217(03)00153-X

Nasiri, H., Alavipanah, S. K., Matinfar, A., Azizi, H. R., \& Hamzeh, M. (2012). Implementation of Agricultural Ecological Capability Model Using Integrated Approach of PROMETHEE II and Fuzzy-AHP in GIS Environment (Case Study: Marvdasht county), Journal of Environmental Studies, 38, 109-122.

Omidi, M., Razavi, H., \& Meh Paikar, M. (2011). Selection of Project Team Members based on Effective Criteria using PROMETHEE Method, Journal of Industrial Management Perspective, 1, 113-134.

Pomerol, J. C., \& Romero, S. B. (2000). Multi-Criterion Decision in Management: Principles and practice, (International Series in Operations Research \& Management Science) Netherlands: Kluwer Academic, Dordrecht. Kluwer, Massachusetts, USA.

Prvulovic, S., Tolmac, D., \& Radovanovic, L. (2011). Application of PROMETHEE-Gaia Methodology in the Choice of Systems for Drying Paltry-Seeds and Powder Materials, Journal of Mechanical Engineering, 57, 778-784. http://dx.doi.10.5545/sv-jme.2008.068

Queiruga, D., Walther, G., Benito, J. G., \& Spengler, T. (2008). Evaluation of sites for the location of WEEE recycling plants in Spain, Waste Management, 28, 181-190. http://dx.doi.10.1016/j.wasman.2006.11.001

Sadeghiravesh, M. H., Ahmadi, H., Zehtabian, G. H., \& Tahmores, M. (2010). Application of analytical hierarchy process (AHP) in assessment of de-desertification alternatives, case study: Khezrabad region, Yazd province. Marta \& Biaban Journal, 17(1),35-51.

Sadeghiravesh, M. H., Khosravi, H., \& Ghasemian, S. (2015). Application of fuzzy analytical hierarchy process for assessment of combating-desertification alternatives in central Iran, Natural Hazards, 75, 653-667. http://dx.doi.10.1007/s11069-014-1345-7

Sadeghiravesh, M. H., Zehtabian, G. H., \& Khosravi, H. (2014). Application of AHP and ELECTRE models for assessment of dedesertification alternatives, Desert, 19, 141-153.

Sadeghiravesh, M. H., Zehtabian, G., Ahmadi, H., \& Khosravi, H. (2012). Using analytic hierarchy process 
method and ordering technique to assess de-desertification alternatives. Case study: Khezrabad, Yazd, IRAN, Carpathian Journal of Earth and Environmental Sciences, 7, 51 - 60.

Safari, H., Sadat Fagheyi, M., Sadat Ahangari, S., \& Fathi, M. R. (2012). Applying PROMETHEE Method based on Entropy Weight for Supplier Selection. Business Management and Strategy, 3, 97- 106.

Shirsikar, S. G., \& Patil, S. (2005). Optimization of energy charges using improved PROMETHEE method, Journal of Electronics and Communication Engineering, 5, 36-42.

Soltanmohammad, H., Osanloo, M., Rezaei, B., \& Aghajani, B. A. (2008). Achieving to some outranking relationships between post mining land uses through mined land suitability analysis, International Journal of Environmental Science and Technology, 5, 535-546.

Taillandier, P., \& Stinckwich, S. (2011). Using the PROMETHEE Multi-Criteria Decision Making Method to Define New Exploration Strategies for Rescue Robots. IEEE International Symposium on Safety, Security, and Rescue Robotics (SSRR), Kyoto: Japan.

\section{Copyrights}

Copyright for this article is retained by the author(s), with first publication rights granted to the journal.

This is an open-access article distributed under the terms and conditions of the Creative Commons Attribution license (http://creativecommons.org/licenses/by/3.0/). 